\title{
Formation of Composite Polyaniline and Graphene Oxide by Physical Mixture Method
}

\author{
Ludmila Resende Vargas, Anne Karoline Poli , Rita de Cássia Lazzarini Dutra', Camila Brito de \\ Souza $^{2,3}$, Maurício Ribeiro Baldan ${ }^{1,4}$, Emerson Sarmento Gonçalves ${ }^{1,2}$
}

\begin{abstract}
The development of polyaniline and graphene oxide composites aims to join the unique properties of each material for aerospace applications. The present paper demonstrates an easy and quick method, compared to the ones found in the literature, to obtain a composite made with polyaniline doped with dodecylbenzenesulfonic acid, a combination commonly called polyaniline, and graphene oxide. Nowadays, the most common studied methods are electrochemistry and in situ chemical polymerization. Differently from these methods, the films were obtained by a physical mixture of equimolar suspension of graphene oxide ( $4 \mathrm{mg} / \mathrm{mL}$ ) with 3 concentrations of polyaniline powder: 25; 50 and $75 \%$, being compared to pure graphene oxide and polyaniline. The morphology and structure behavior of all the films were studied, besides the bonding nature between both materials. The films were analyzed by scanning electron microscopy, X-ray diffraction, Fourier transform infrared spectroscopy, and differential scanning calorimetry. The apparent interaction between graphene oxide corrugated sheets and polyaniline grains was verified by scanning electron microscopy images. It can be noticed, as the concentration of polyaniline increases, that more polymer was entrapped. To prove the formation of polyaniline/graphene oxide composite, X-ray diffraction and Fourier transform infrared spectroscopy techniques demonstrated the changes on graphene oxide crystallographic plans and on the chemical bonding between polyaniline and graphene oxide, suggesting an interaction between polyaniline and graphene oxide, especially in the composite with $50 \%$ polyaniline $/ 50 \%$ graphene oxide. Differential scanning calorimetry was used to highlight this effect through the increase in thermal stability. The method of physical mixture was efficient to obtain the polyaniline/ graphene oxide composites.
\end{abstract}

KEYWORDS: Graphene oxide, Polyaniline, Structure, Morphology, FT-IR, DSC.

\section{INTRODUCTION}

The search for innovative technologies in the area of electronics and electromagnetic absorbing materials has grown in the last few years (Singh et al. 2011; Mi et al. 2008; Kim et al. 2010). Materials that combine good electric properties, thermal stability (Feng et al. 2011), and low cost of production are used as initial requirements for the development of new materials.

The development of polyaniline (PAni) and graphene oxide (GO) composites aims to join the unique properties of each material and to obtain a composite with better performance than the original materials. These composites can be easily applied in aerospace industry devices, such as sensors, radar absorbing systems (RAS), and energy storage elements. Both materials present special properties that can be changed according to their manufacturing parameters.

As described by Wang et al. (2009), graphene (GE) and materials based on it (GO and reduced GO - rGO) have attracted even more attention thanks to their applications as energy storage devices (Wei et al. 2015; Yang et al. 2013). GO can be considered the most common graphene-based material produced in large scale and at a lower cost.

Differently from GE, GO presents oxygenated, hydrophilic functional groups and can be easily dispersed in aqueous solution (Dreyer et al. 2010), facilitating the interaction between GO and PAni. Gupta et al. (2013) describe the GO as a material that presents a planar structure of oxidized carbon with $\mathrm{sp}^{2}$ hybridization, rich in oxygen groups, such as hydroxyl, carboxyl, 
and epoxides. Dreyer et al. (2010) consider that the presence of these groups can be used as a good site for surface modification.

Regarding PAni and its special chemical property of doping and dedoping (ranging from acidic to basic medium), Feng et al. (2011) and Rakic et al. (2011) showed its suitable environmental stability and application versatility. This polymer can be produced in several oxidation states (leucoemeraldine, emeraldine, pernigraniline), each one characterized by a different structure, with several electrical properties and the ability to be produced by chemical or electrochemical synthesis (Tamburria et al. 2011; Maia et al. 2000; Sapurina and Stejskal 2010; Ćirić-Marjanović 2013). The formation of conductive structures in the polymer is shown in Fig. 1.

(a)

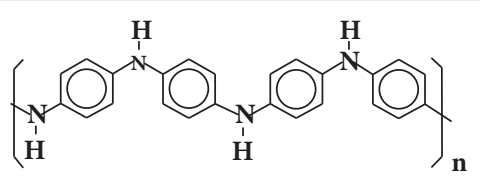

(b)

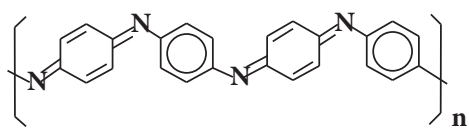

(c)

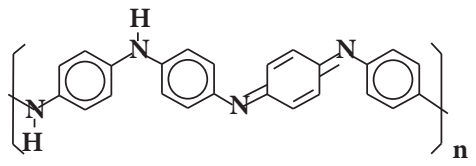

(d)

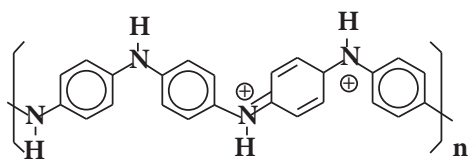

Figure 1. Linear structure of PAni and its several oxidation states. (a) Leucoemeraldine; (b) Pernigraniline; (c) Emeraldine; (d) Protoned emeraldine (Padilha 2011).

When the emeraldine base is doped in an acid environment, a polaron or bipolaron can be formed through successive formations of positive species. Bipolaron structures are thermodynamically more stable and conductive (Bockris and Reddy 2004). As mentioned by Bhadra et al. (2009), these polarons are responsible for electrical conduction through a jumps mechanism in the crystalline polymer region. The adjacent nitrogen electron (neutral) moves to a vacant spot and neutralizes it. Consequently, this spot moves, creating new spaces in the nitrogen structure and in the polarons structures, resulting in electron transportation and, thus, electrical conductivity along the chain (Bockris et al. 2004).
Recently, the PAni/GO composition was successfully synthesized by electrochemical and chemical methods applied to obtain supercapacitor materials (Wang et al. 2009). In this paper, a composite was obtained through a physical mixture of PAni and GO in suspension. The aim is to achieve, through this simple method, the formation of a PAni/GO composite and to study the potential interaction between PAni polar groups and the graphenic structure. The morphological, structural, chemical, and thermal aspects were analyzed. Furthermore, low-cost factors to develop a high-quality composite using innovative methods and processes were considered in the present study.

\section{METHODOLOGY POLYANILINE SYNTHESIS}

The PAni synthesis was carried out through aniline monomer oxidation (1.0 mol/L aqueous solution) with ammonium persulfate $(1.9 \mathrm{~mol} / \mathrm{L})$, in $1.0 \mathrm{~mol} / \mathrm{L}$ solution of hydrochloric acid and sodium chloride. The solution was kept in a reactor at $-5^{\circ} \mathrm{C}$ under constant stirring, immersed in a bath of $1.0 \mathrm{~L}$ capacity with ethylene glycol in a temperature around $-40{ }^{\circ} \mathrm{C}$, while the ammonium persulfate solution was added during $50 \mathrm{~min}$.

A dark green precipitate in the solution was observed, indicating the formation of PAni doped with $\mathrm{HCl}$. After the complete addition of oxidizer, the system was left under mechanical stirring for $2 \mathrm{~h}$. The polymer was removed from the reactor and washed several times with an 50\% v/v ethanol/ distilled water solution and a basic solution of $\mathrm{NH}_{4} \mathrm{OH}$ (1.0 mol/L).

After dedoping, the material was washed with a $50 \% \mathrm{v} / \mathrm{v}$ ethanol/distilled water solution several times and filtered to obtain a particulate powder (base form of pure PAni).

It was added a quantity of $5 \mathrm{~g}$ of PAni in an aqueous solution containing $9 \mathrm{~g}$ of dodecylbenzenesulfonic acid (DBSA); this solution was left under constant stirring for $24 \mathrm{~h}$ at room temperature. The doped PAni-DBSA was washed with distilled water and ethyl alcohol, filtered, and the green powder was dried under vacuum at $60^{\circ} \mathrm{C}$ until constant weight. The doping with functionalized DBSA was carried out by a solution method in the molar ratio 1:8 of PAni/DBSA. The PAni doped with this acid is referred to as "PAni" throughout this paper.

\section{POLYANILINE/GRAPHENE OXIDE COMPOSITE}

The cited method aims to verify the impact of solvent action in the composite formation. Furthermore, it is not previously 
described in the literature, and the interaction effects need to be confirmed.

Composites were prepared with doped PAni (2 h; 200 mesh/ $325 \mathrm{mesh})$ and GO from SIGMA-ALDRICH $(4 \mathrm{mg} / \mathrm{mL}$ in water dispersion). Initially, the desired amount of PAni powder was transferred into a $10 \mathrm{~mL}$-beaker and the mixture with GO; $5 \mathrm{~mL}$ of this mixture were transferred to a Petri dish and dried in a vacuum oven at $40{ }^{\circ} \mathrm{C}$, resulting in a dried film. The films were obtained after $5 \mathrm{~h}$ of drying using 3 different PAni concentrations (25; 50 and 75\%) that were compared with the original materials - GO and PAni.

\section{CHARACTERIZATION METHODS}

The morphological characterization of the films was performed using Zeiss ${ }^{\circledR}$ Leo 440 scanning electron microscopy (SEM), and the crystallographic structures of the films were analyzed using Panalytical ${ }$ X-ray diffractometer (XRD), a rotating anode $\mathrm{X}$-ray generator working at $5^{\circ} \leq 2 \theta \leq 90^{\circ}$, with $\mathrm{Cu}$ monochromatic radiation $(0.154 \mathrm{~nm})$. Functional groups were determined by Fourier transform infrared (FT-IR) spectroscopy using PerkinElmer ${ }^{\circledR}$ Spectrum One spectrometer. The samples were prepared as $\mathrm{KBr}$ pressed pellet samples, and the FT-IR spectra were obtained by transmission mode from 4000 to $400 \mathrm{~cm}^{-1}$. Differential scanning calorimetry (DSC) data were obtained with PerkinElmer ${ }^{\circledR}$ Pyris 1 , at a heating rate of $5{ }^{\circ} \mathrm{C} / \mathrm{min}$ in nitrogen atmosphere.

\section{RESULTS AND DISCUSSION SCANNING ELECTRON MICROSCOPY}

The material morphology was studied by SEM. Figure 2 shows the original materials and the films that were obtained with the different ratios of PAni. The corrugated structures refer to the GO (Fig. 2a), and the granular ones, to the PAni (Fig. 2b). The corrugated structures are microscopically-oriented and grouped with a certain degree of parallelism, which was broken as the polymer was added. For all the different ratios of GO/PAni, the PAni was homogeneously surrounded by GO fibers. This morphology remains similar, in greater or lesser intensity, for all GO/PAni ratios.

This encapsulation effect appears more evident in the proportions of 50 and $75 \%$ of PAni, as shown in Figs. 2d and 2e. The interaction between PAni and corrugated sheets of GO can be easily noticed, as well as corrugated structures are localized between PAni particles, which can be partially encapsulated as demonstrated in Fig. 3. In all cases, the GO acts as a placental structure, very thin and transparent, and involves most of the PAni particles. This fact may be explained by the presence of

(a)

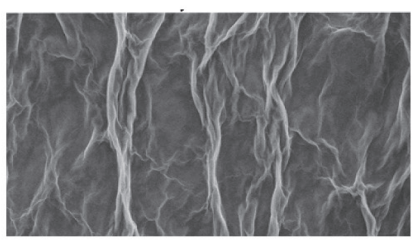

(b)

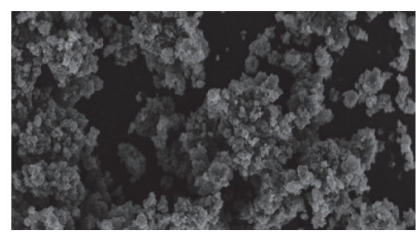

(c)

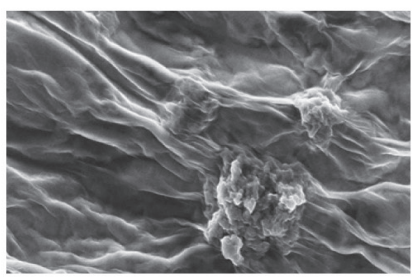

(d)

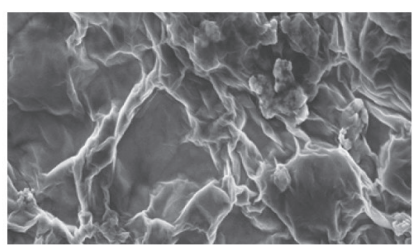

(e)

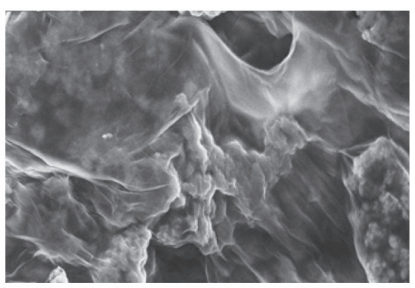

Figure 2. SEM of PAni, GO and their mixture (scale $10 \mu \mathrm{m}$ ). (a) GO (1,800X); (b) PAni $(1,000 X)$; (c) PAni 25\%/G0 75\% (2,700X); (d) PAni 50\%/GO 50\% (2,700X); (e) PAni 75\%/GO 25\% (3,000X).

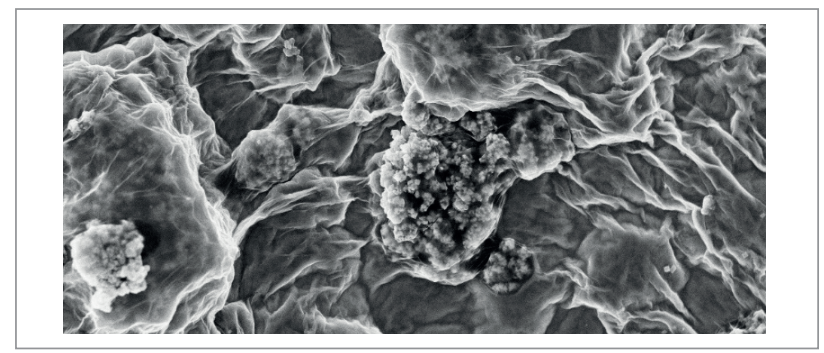

Figure 3. SEM of PAni 50\%/GO 50\% composite. 
a solvent action (deionized water) to connect and encapsulate the PAni particles.

There is evidence of interactions between PAni and GO structures, so the nature of their bonds is not conclusive. Wang et al. (2010) made a relevant contribution and raised possible chemical bonds and electrostatics interactions between PAni and GO. They suggested a chemical synthesis of PAni/GO composites and its interactions using XRD and FT-IR techniques. With a different synthesis method compared with that of Wang et al. (2010), the present paper intends to analyze the existence of chemical bonds between PAni and GO, proving the composite formation.

As shown in Fig. 4, some interactions are noticed. By combining the results of UV-vis absorption, Raman spectra, and XPS analysis, Wang et al. (2010) proposed that the interaction of GO/PAni can be divided into 3 major interactions: (a) $\pi-\pi$ stacking; (b) electrostatic interactions; and (c) hydrogen bonding. In order to get the best of both materials, it is important to understand the interaction between GO and PAni to exploit the potential for supercapacitor applications. The interaction between polar groups (polymer charge carriers) and oxygenated groups of GO results in the possible formation of ionic or coordinated complexes. In addition, hydrogen bonds may be formed between the nonprotonated amine groups with hydroxyl hydrogen atoms. This

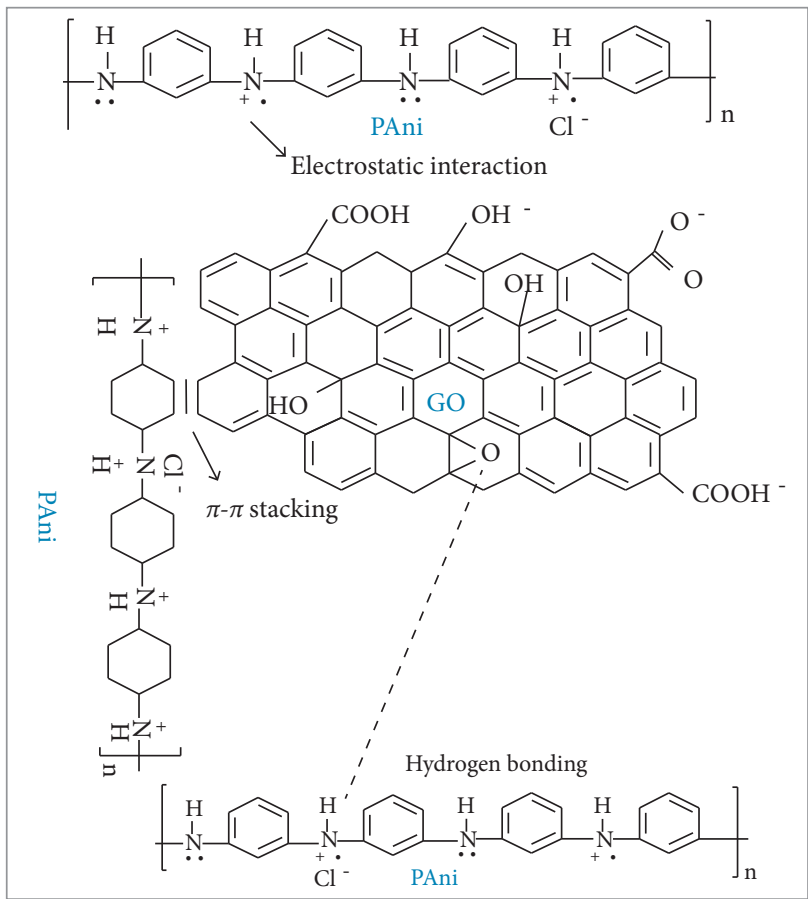

Figure 4. Possible interaction between PAni and GO structures, adapted from Wang et al. (2010). can also occur between epoxide groups and hydrogen atoms attached to electrically-charged nitrogen (Wang et al. 2010).

\section{X-RAY DIFFRACTION}

The structure of the composites was investigated by powder $\mathrm{XRD}$ measurements. The XRD spectra were measured in a range of $2 \theta$ from $5^{\circ}$ to $70^{\circ}$, showing an intense and sharp peak at $2 \theta=8.7^{\circ}(\mathrm{GO})$ corresponding to the interplanar space of GO sheets. The reflection peak can be assigned to (001). According to Blanton and Majumdar (2013), the $2 \theta$ peak of GO can shift from $7^{\circ}$ to $12^{\circ}$, depending on the amount of residual water that can be intercalated between the basal planes. Zhang et al. (2010) reported that the reflection peak might depend on 2 major contributions: the method of preparation and the number of layers of water below the GO surface film. Michell et al. (2015) observed that the characteristic peak of the graphite used to synthesize the graphite oxide shifts from $2 \theta=26.4^{\circ}$ to $2 \theta=10.61^{\circ}$. This shift was attributed to oxygenated groups and water molecules inserted in the interlayer of graphite. It is important to remember that GO has a 2-D form of graphite and presents oxygen function groups in its basal planes and edges providing compatibility with polymer matrices. The GO surface acts as a nucleation site for the PAni due to oxygen functional groups on GO surface. The tuning of the amount of PAni in GO introduced some interesting aspects in XRD and in the morphology (Fig. 2). After the formation of GO/PAni, it is observed that the GO peak height intensity shows a very strong decrease. Furthermore, the peak broadening is very apparent for all the 3 compositions of GO/PAni (inset of Fig. 5). Another interesting aspect is that the peaks shift to

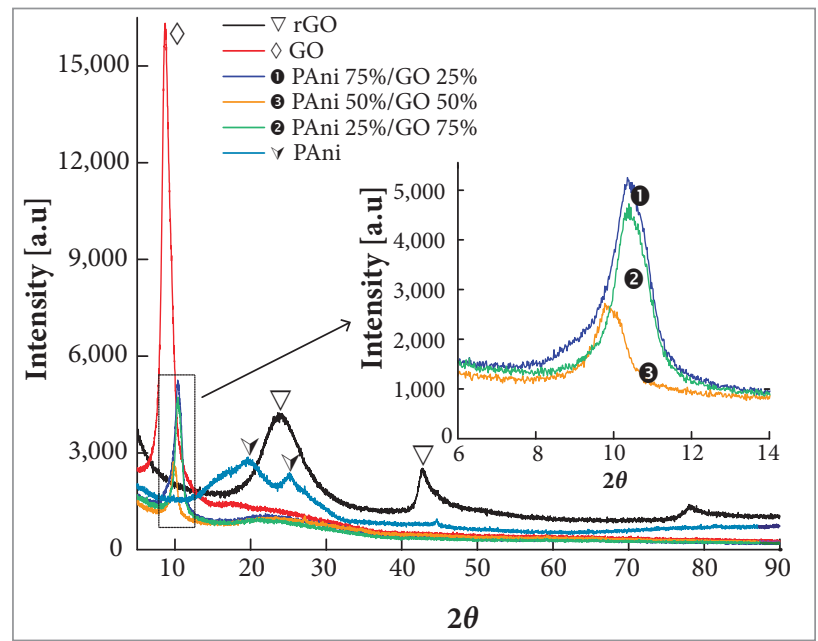

Figure 5. XRD of PAni/GO composites. 
a higher $2 \theta$. Singh et al. 2011 observed the decrease in GO height peak. According to them, the GO peak decreases its height intensity when residual water is removed from the GO surface, which suggests a possible interaction between PAni and GO that may be influenced by water content or oxygen function groups on the GO surface. The pure PAni exhibits 2 important reflection peaks, $2 \theta=2 \theta^{\circ}$ and $2 \theta=25^{\circ}$, that can be associated to some crystalline order in the bulk PAni. The PAni reflection peaks decrease drastically during the formation process of GO/PAni, which was revealed by the shallow reflection in just one peak around $2 \theta=21^{\circ}$. This change is associated with PAni/GO interaction and crystallographic sheets changes. The combination of the substantial shift of the PAni, in the formation process of PAni/GO, and the decrease in GO peak height intensity justify the formation of a hybrid composite. By analyzing the XRD of the 3 compositions (PAni 25\%/GO 75\%, PAni 50\%/GO 50\% and PAni 75\%/GO 25\%), a new, broad, and minor peak appears indicating the intercalation of PAni between GO sheets.

The broadening of the peaks is evident for all the PAni/ GO compositions studied in this paper. Due to the interaction between PAni and GO, the material structure may change and affect their thermal and mechanical stability. In order to confirm the nature of these interactions, the FT-IR and DSC techniques are discussed next.

\section{FOURIER TRANSFORM INFRARED SPECTROSCOPY}

FT-IR spectroscopy was used to elucidate the nature of the interaction between PAni and GO. Figure 6 shows the spectra of PAni, GO, and of their mixtures. It is possible to observe the greatest similarity between the spectra of PAni 25\%/GO 75\% and the spectra of GO. The samples containing PAni 50\%/GO 50\% and PAni 75\%/GO 25\% demonstrated similarity with the PAni, especially PAni 50\%/GO 50\%, suggesting that the interaction effect achieved an optimized level.

All contributions were grouped in 10 different items as shown in Table 1. The main spectra changes in the medium infrared region (MIR) are included in Table 1 as well. In order to analyze and compare all the spectra, they were divided into different intervals in this region. It is very important to notice that, in MIR region, from 4000 down to $1800 \mathrm{~cm}^{-1}$, the spectra showed a broad and intense band related to stretching $\mathrm{O}-\mathrm{H}$ and $\mathrm{N}-\mathrm{H}$ in hydroxyl and amine groups, respectively. In addition, the presence of moisture in $\mathrm{KBr}$ pads, used to perform the experiment by transmittance or humidity from GO, could contribute to this. The band may be associated to hydrogen bond between NH from PAni and possible oxygenated group from GO. The behavior of the $\mathrm{OH}$ group can suggest electrostatic interaction (Smith 1979), and the relevant FT-IR bands in the MIR region are shown in Table 1 (item 1 ).

In the range from 1,800 to $1,600 \mathrm{~cm}^{-1}$, it is possible to analyze the $\mathrm{GO}$ spectrum and its consequences in the presence of different PAni/GO compositions (Table 1, items 2 and 3). Probably, $\pi-\pi$ stacking is a predominant effect, which moves electrons preferably from GO to PAni structure. The main bands at 1720 and $1630 \mathrm{~cm}^{-1}$ in the spectrum of GO are related to $\mathrm{C}=\mathrm{O}$ stretching in $\mathrm{COOH}$ group and $\mathrm{C}=\mathrm{C}$ in aromatic rings, respectively. However, $1630 \mathrm{~cm}^{-1}$ band may be associated to vibrations of the residual water mainly coming from $\mathrm{KBr}$ pads. This effect certainly masks the analysis of this band. It is possible to notice the constant presence of these bands for all PAni/GO compositions. Furthermore, a noticeable blueshift at 1720 and $1630 \mathrm{~cm}^{-1}$ regarding PAni 50\%/GO 50\% was observed (Fig. 7), which may be related with 2 phenomena: electrostatic attraction of carboxylic oxygen and $\pi-\pi$ stacking from $C=C$ supplied from graphene sheets to benzenoid structure of PAni, once the

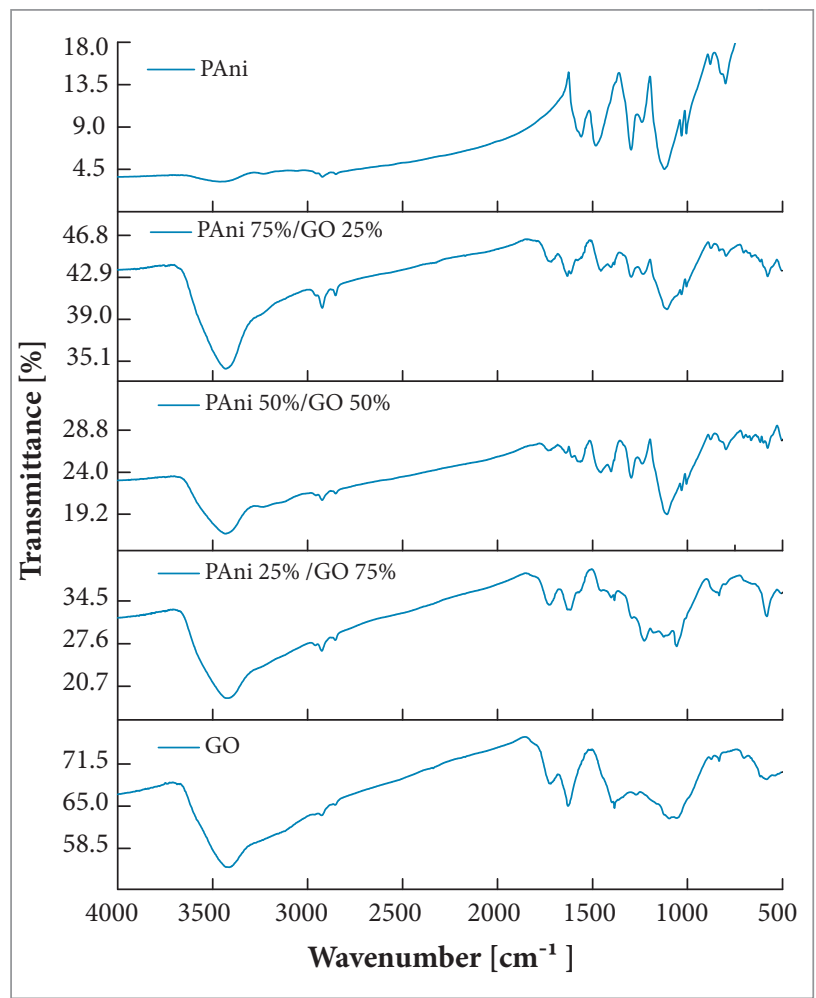

Figure 6. Transmission MIR spectra of PAni/GO, prepared as $\mathrm{KBr}$ pellets. 
Table 1. More relevant FT-IR bands to the obtained composites.

\begin{tabular}{|c|c|c|c|c|c|c|c|c|}
\hline Item & $\begin{array}{c}\mathrm{GO} \\
{\left[\mathrm{cm}^{-1}\right]}\end{array}$ & $\begin{array}{l}\text { PAni } \\
{\left[\mathrm{cm}^{-1}\right]}\end{array}$ & $\begin{array}{l}25 \% \text { PAni } \\
\text { [DBSA]/ } \\
75 \% \text { GO } \\
{\left[\mathrm{cm}^{-1}\right]}\end{array}$ & $\begin{array}{l}50 \% \\
\text { PAni } \\
{[\text { DBSA]/ }} \\
50 \% \text { GO } \\
{\left[\mathrm{cm}^{-1}\right]}\end{array}$ & $\begin{array}{l}75 \% \\
\text { PAni } \\
\text { [DBSA]/ } \\
25 \% \text { GO } \\
{\left[\mathrm{cm}^{-1}\right]}\end{array}$ & $\begin{array}{l}\text { Wavenumber } \\
\text { shift }\end{array}$ & $\begin{array}{l}\text { Changing on form } \\
\text { and intensity }\end{array}$ & $\begin{array}{c}\text { Attribution } \\
\text { and probable effects } \\
\text { [Wang et al. 2009; Smith 1979] }\end{array}$ \\
\hline 1 & 3413 & 3442 & 3422 & 3431 & 3431 & $\begin{array}{c}\text { In relation } \\
\text { to GO, it } \\
\text { increased with } \\
\text { the increasing } \\
\text { in PANI ratio; } \\
\text { in relation to } \\
\text { PAni spectrum, } \\
\text { a decrease was } \\
\text { observed }\end{array}$ & $\begin{array}{l}\text { Widening observed } \\
\text { for PAni } 50 \% / \\
\text { GO } 50 \% \text { and band } \\
\text { higher than others } \\
\text { for PAni } 75 \% / G O \\
25 \%\end{array}$ & $\begin{array}{c}-\nu \mathrm{OH}(\mathrm{GO}) \text { and } v \text { NH (PAni/ } \\
\text { DBSA), referring to hydrogen bond } \\
\text { between NH from PAni and possible } \\
\text { oxygenated group from GO, except } \\
\text { hydroxyl (possibly carboxyl or } \\
\text { epoxyde). The behavior of OH group } \\
\text { can suggest electrostatic interaction. } \\
\text { Furthermore, there is a possible } \\
\text { overlap with humidity from KBr pad } \\
\text { (Smith 1979) }\end{array}$ \\
\hline 2 & 1720 & --- & 1727 & 1734 & 1717 & $\begin{array}{l}\text { Highest value } \\
\text { for PAni } 50 \% \text { / } \\
\text { GO } 50 \%\end{array}$ & $\begin{array}{c}\text { The lowest } \\
\text { intensity for PAni } \\
50 \% / \text { GO } 50 \%\end{array}$ & $\begin{array}{c}v \mathrm{C}=\mathrm{O} \text { in } \mathrm{COOH} \text { from } \mathrm{GO} \text {, which } \\
\text { may pass to } \mathrm{C}=\mathrm{O} \text { similar to ester } \\
\text { (Smith 1979). Suggested changing } \\
\text { on mode of electrostatic interaction. } \\
\text { Possible action of DBSA (PAni } \\
\text { dopant) }\end{array}$ \\
\hline 3 & 1630 & ---- & 1616 & 1641 & 1632 & $\begin{array}{l}\text { The lowest value } \\
\text { for PAni } 25 \% / \\
\text { GO75\% and the } \\
\text { highest for PAni } \\
50 \% / \text { GO } 50 \%\end{array}$ & $\begin{array}{l}\text { Intensity decreases, } \\
\text { especially for PAni } \\
50 \% / \text { GO } 50 \%\end{array}$ & $\begin{array}{c}\pi-\pi \text { stacking, possibly masked to } \\
\text { PAni } 50 \% / G O 50 \% \text { by } \mathrm{KBr} \text { humidity }\end{array}$ \\
\hline 4 & --- & 1559 & $\begin{array}{l}\text { Shoulder } \\
\text { at } 1559\end{array}$ & 1564 & $\begin{array}{l}\text { Shoulder } \\
\text { at } 1556\end{array}$ & No variation & $\begin{array}{l}\text { The highest value } \\
\text { for PAni } 50 \% / \mathrm{GO} \\
50 \%\end{array}$ & $\begin{array}{c}\text { Quinoid structure }(\mathrm{N}=\mathrm{Q}=\mathrm{N}) \text { in } \\
\text { aniline oligomers (Wang et al. 2009; } \\
\text { Tang 1988) }\end{array}$ \\
\hline 5 & --- & 1481 & $\begin{array}{l}\text { Shoulder } \\
\text { at } 1465\end{array}$ & 1457 & 1457 & Decrease & $\begin{array}{l}\text { It is visible for PAni } \\
50 \% / G O 50 \% \text { and } \\
\text { PAni } 75 \% / G O 25 \%\end{array}$ & $\begin{array}{c}\pi(C=C) \text { in benzenoid ring }(\mathrm{N}-\mathrm{B}-\mathrm{N}) \\
(\text { Tang } 1988 \text {; Dmitrieva and Dunsch } \\
\text { 2011). Wang et al. }(2009) \text { suggest } \pi-\pi \\
\text { stacking }\end{array}$ \\
\hline 6 & 1385 & --- & 1385 & 1384 & 1385 & No variation & $\begin{array}{l}\text { Apparently, } \\
\text { intensity decreased } \\
\text { until maximize } \\
\text { PAni ratio }\end{array}$ & $\begin{array}{c}\delta \mathrm{OH} \text { acid and } \delta \mathrm{OH} \text { phenol }(\mathrm{GO}) \\
(\text { Smith 1979) }\end{array}$ \\
\hline 7 & --- & 1297 & $\begin{array}{l}\text { Shoulder } \\
\text { at } 1297\end{array}$ & 1296 & 1296 & No changes & $\begin{array}{l}\text { The highest value } \\
\text { for PAni } 50 \% \text { / } \\
\text { GO } 50 \%\end{array}$ & $\begin{array}{c}\text { v } \mathrm{C}-\mathrm{N} \text { in } \mathrm{QB}_{\text {cis }} \mathrm{Q}, \mathrm{QBB}, \mathrm{BBQ} \text { (Wang } \\
\text { et al. 2009) and v C-N secondary } \\
\text { aromatic amine (Smith 1979) }\end{array}$ \\
\hline 8 & ---- & 1240 & 1232 & 1239 & 1234 & $\begin{array}{l}\text { The lowest } \\
\text { value for PAni } \\
25 \% / \text { GO } 75 \%\end{array}$ & $\begin{array}{l}\text { Apparently, the } \\
\text { highest value for } \\
\text { PAni } 50 \% / \text { GO } 50 \%\end{array}$ & $\begin{array}{l}v \mathrm{C}-\mathrm{N} \text { in BBB (Wang et al. } 2009 \text { ). } \\
\text { Probably performing on } \pi-\pi \text { stacking }\end{array}$ \\
\hline 9 & --- & 1122 & 1125 & 1108 & 1108 & Decrease & $\begin{array}{c}\text { The highest } \\
\text { intensity for } \\
\text { PAni } 50 \% / \text { GO } 50 \%\end{array}$ & $\begin{array}{l}1,170-1,140 \mathrm{~cm}^{-1} \text { refers to } \\
\text { vibrational mode } \mathrm{Q}=\mathrm{NH}^{+}-\mathrm{B} \text { or } \\
\mathrm{B}-\mathrm{N}^{+} \mathrm{H}-\mathrm{B} \text { (related to electrical } \\
\text { conductivity). At } 1,115 \mathrm{~cm}^{-1} \text {, } \\
\text { substituting } 1,2,4 \text { of ring (Zeng and } \\
\text { Ko } 1998 \text {; Tang } 1988 ; \text { Dmitrieva and } \\
\text { Dunsch } 2011 \text { ). It can be related to } \\
\pi-\pi \text { stacking and hydrogen bonds } \\
\text { with oxygen groups from GO }\end{array}$ \\
\hline 10 & --- & 800 & $\begin{array}{l}\text { Shoulder } \\
\text { at } 800\end{array}$ & 798 & 797 & No variation & $\begin{array}{l}\text { The highest value } \\
\text { for PAni } 50 \% / \mathrm{GO} \\
50 \%\end{array}$ & $\begin{array}{l}\text { Substituting 1,4 of ring (Wang et al. } \\
2009 \text { and Smith 1979) }\end{array}$ \\
\hline
\end{tabular}


blueshift of this band may be related to decreased availability of electrons $\pi$ in graphenic rings.

Concerning the second region (Fig. 8), in the range from 1,600 to $1350 \mathrm{~cm}^{-1}$, the bands at 1481 and $1559 \mathrm{~cm}^{-1}$ are assigned to $\mathrm{C}=\mathrm{C}$ in benzenoid and quinoid structures, respectively. The $1481 \mathrm{~cm}^{-1}$ mode in the PAni spectrum was redshifted from its position for all PAni/GO combinations. The blueshift for the mode $1559 \mathrm{~cm}^{-1}$ in combination with a decrease in the benzoid structure may be associated to the greater electron availability from GO in the $\pi-\pi$ stacking. Besides, the electron availability contributes to the reduction of quinoid structures. This behavior was described in Table 1 (items 4 and 5).

The band at $1296 \mathrm{~cm}^{-1}$ (Fig. 9), observed in the PAni spectrum, was attributed to $\mathrm{C}-\mathrm{N}$ stretching of secondary amine in $\mathrm{QB}_{\mathrm{cis}} \mathrm{Q}, \mathrm{QBB}$, and BBQ units (Table 1, item 7). It can

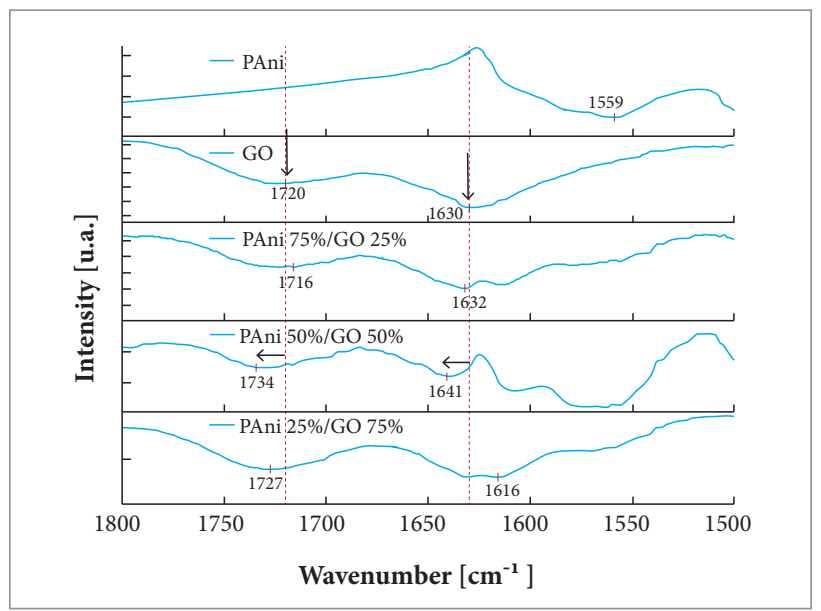

Figure 7. FT-IR partial spectra: first significant region of MIR for PAni/GO composites.

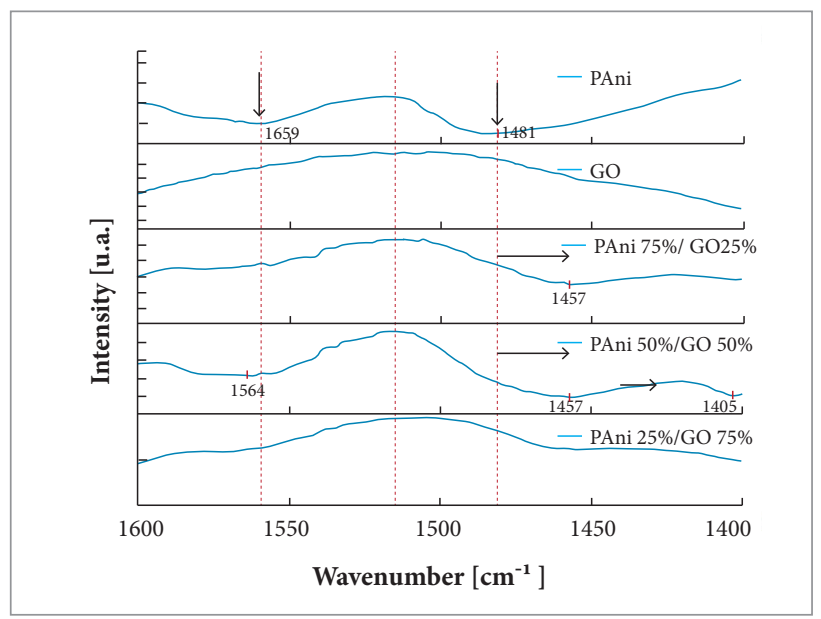

Figure 8. FT-IR partial spectra: second significant region of MIR for PAni/GO composites. be observed that this band is more evident for the PAni 50\%/ GO 50\%. This effect is related to the alternation of benzenoid and quinoid structures. The next band, at $1240 \mathrm{~cm}^{-1}$ (Fig. 9), is related to $\mathrm{C}-\mathrm{N}$ stretching in $\mathrm{BBB}$ units (and it is a result of the reduction from quinoid to benzenoid structures, as discussed next, coherent with the proportion between the bands 1,564 and $1457 \mathrm{~cm}^{-1}$ ) and is decreased for this composition.

The band at $1122 \mathrm{~cm}^{-1}$ (Fig. 9) may be associated to $p$ electron cloud in PAni chain (Table 1, item 9). No relative increase was observed for the charged polymer unit $\mathrm{Q}=\mathrm{NH}^{+}-\mathrm{B}$ or $\mathrm{B}-\mathrm{N}^{+} \mathrm{H}-\mathrm{B}$. This structure may be suited to evaluate the degree of doping. As can be observed, this effect is more pronounced in PAni 50\%/GO 50\%, indicating that this composition favors a conductivity greater than the others.

According to Table 1, all effects noticed in the literature are present, but with predominance of $\pi-\pi$ stacking. Concerning GO bands, shifts are observed for higher values of wavenumber, while, for PAni, values decrease in contrast to those outlined by Wang et al. (2009). However, the techniques and orders of magnitude of ratios are radically different. The effects observed in the interaction are more highlighted for the composite PAni 50\%/GO 50\%.

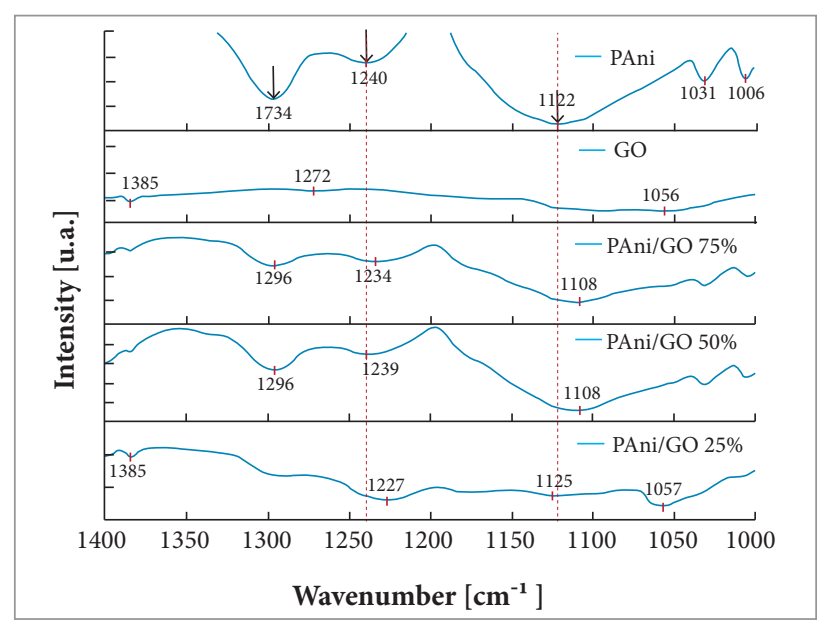

Figure 9. FT-IR partial spectra: third significant region of MIR for PAni/GO composites.

\section{DIFFERENTIAL SCANNING CALORIMETRY}

The thermal analysis was made in order to study the thermal stability of the PAni/GO composites. Energy variation behavior can be associated to possible links between groups of PAni and GO.

According to DSC analysis, PAni exothermic peaks are associated to cross-linking reactions during the annealing process, as observed by Cheng (2002). This author attests that 
PAni may suffer a change in conformation or reticulation reaction above $100^{\circ} \mathrm{C}$. An increase from $107^{\circ} \mathrm{C}$ (Fig. 10) up to around $180^{\circ} \mathrm{C}$ (Fig. 11) was observed for this peak temperature when PAni was combined with GO.

These data indicate the formation of PAni cross-links. However, in the presence of GO, there is an engagement of PAni $p$ electrons in a stacking with GO aromatic structures, decreasing their availability to obtain $s$ bonds of cross-linking. Due to this fact, the cross-linking reaction is thermodynamically disfavored at temperatures below $170{ }^{\circ} \mathrm{C}$, probably because these interactions. This effect is more evident in PAni 50\%/GO 50\%, which showed a cross-linking temperature higher than that of PAni alone. In all compositions of PAni/GO, a very strong increasing in the process enthalpy was noticed. The jumping from $-94.3 \mathrm{~J} / \mathrm{g}$ (Fig. 10) up to values between 2 and 7 times more than that, inversely proportional to the concentration of PAni (Fig. 11), highlights the effect of entrapment of PAni by $\mathrm{GO}$ and its difficulty to form cross-linkings, when trapped by GO. This effect indicates that the stability of PAni/ $\mathrm{GO}$ is possibly valid to space application because of normative limitation. For example, the European Aerospace

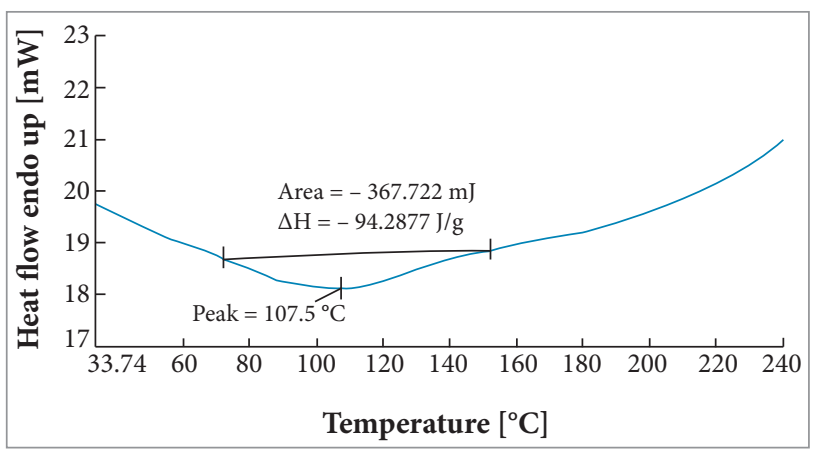

Figure 10. DSC thermogram of doped PAni.

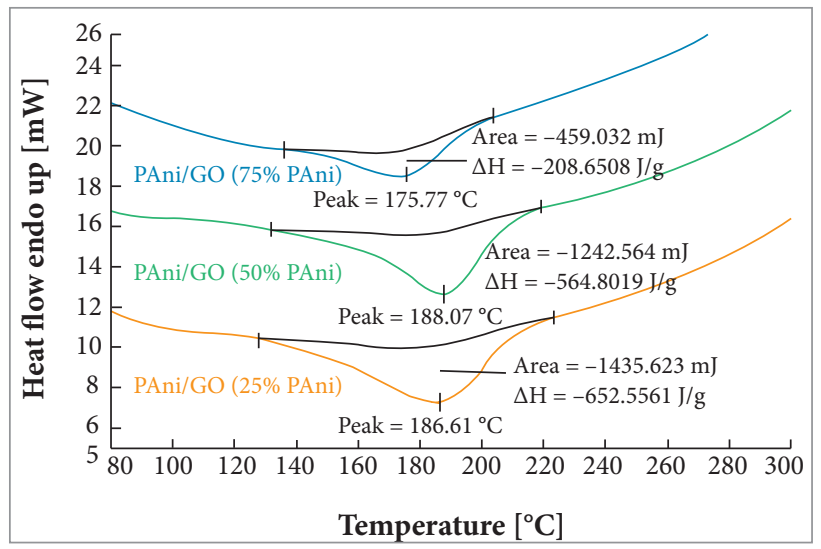

Figure 11. DSC of PAni/GO composites in different ratios.
Norms EN 4644-011:2015-8, EN 4644-013:2015-08, and EN 4644-131:2015-8 determine that aerospace materials must resist temperatures below $175^{\circ} \mathrm{C}$. For aeronautic applications, MIL-STD-810 determines that the materials must be stable until $85^{\circ} \mathrm{C}$. So, for aerospace application, PAni/GO seems to be more suitable than PAni.

The GO does not have an exothermic peak, as illustrated in Fig. 12, but an endothermic one can be noted, which merely indicates loss of water and, therefore, does not interfere in the composite thermal stability.

The evidence of electronic interactions of $\pi-\pi$ stacking on composites was strongly confirmed by DSC, and the method of physical mixture has proven relatively easy and successful to obtain PAni/GO composites.

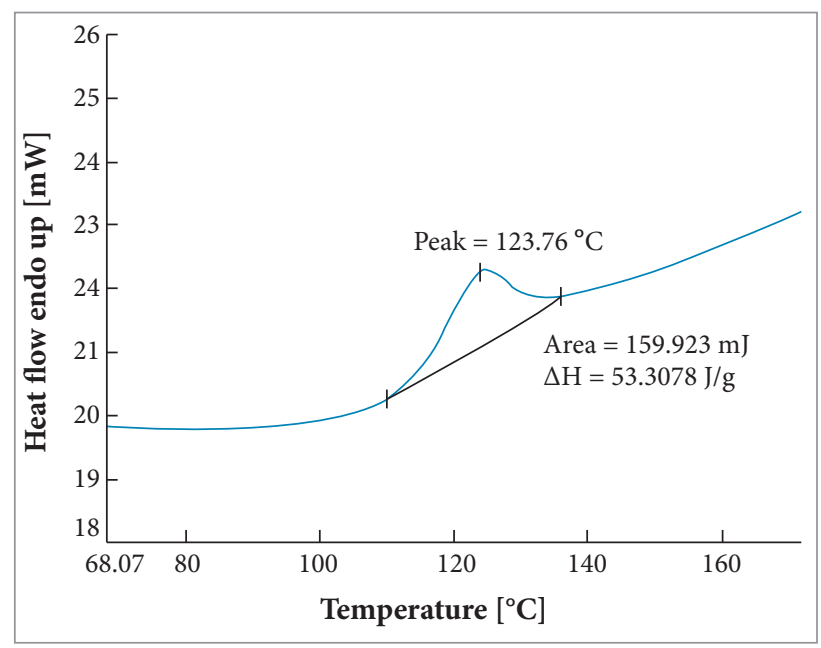

Figure 12. DSC of GO.

\section{CONCLUSION}

Through the experiments conducted with the used composite formulation, it is noticed that there is an increase in the attraction intensity of the corrugated GO and PAni particles through solvent action. However, this behavior is not linear.

It can be seen, within the examined range, that this effect is most pronounced in the PAni 50\%/GO 50\% composite. XRD tests show important interactions that occur between PAni structure and oxygen groups from GO, provoking a possible crystallographic rearrangement. This occurs, according to FT-IR data set, because of the important interaction between PAni and graphene structure, due to predominant $p$ - $p$ stacking; however, other effects may be 
observed (electrostatic interactions and, in lower incidence, hydrogen bonds). The thermal effect of this interaction is the formation of a more stable conformed PAni, disfavoring cross-linking reactions and improving the composite thermal stability, which, around $175^{\circ} \mathrm{C}$, is desirable for aerospace applications.

\section{ACKNOWLEDGEMENTS}

The authors would like to thank Andreza de Moura Cardoso, Maria Aparecida Miranda de Souza, Rogério Duque Gonçalves, Aline Fontana Batista, and João Marcos Kruczinski, from the Departamento de Materiais of the Instituto de Aeronáutica e Espaço, for their assistance and support in this project.
Special thanks also go to Milton Faria Diniz, from the Divisão de Química of the Instituto de Aeronáutica e Espaço, and to Coordenação de Aperfeiçoamento de Pessoal de Nível Superior/ Instituto Tecnológico de Aeronáutica, for the research grant PVS process that made this research possible.

\section{AUTHOR'S CONTRIBUTION}

Vargas LR, Dutra RCL, Baldan MR, and Gonçalves ES conceived the idea and co-wrote the main text; Vargas LR, Poli AK, and Souza CB performed the experiments; Vargas LR, Baldan MR, Souza CB, and Gonçalves ES prepared the figures. All authors discussed the results and commented on the manuscript.

\section{REFERENCES}

Bhadra S, Khastgir D, Singha NK, Lee JH (2009) Progress in preparation, processing and applications of polyaniline. Prog Polymer Sci 34(8): 783-810. doi: 10.1016/j.progpolymsci.2009.04.003

Blanton TN, Majumdar D (2013) Characterization of X-ray irradiated graphene oxide coatings using X-ray diffraction, X-ray photoelectron spectroscopy, and atomic force spectroscopy. Powder Diffr 28(2):6871. doi: 10.1017/S0885715613000109

Bockris JO, Reddy AKN (2004) Modern electrochemistry. 2nd edition. New York: Kluwer Academic Publishers.

Cheng $\mathrm{CH}$ (2002) Thermal studies of polyaniline doped with dodecyl benzene sulfonic acid directly prepared via aqueous dispersions. J Polymer Res 9(3):195-200. doi: 10.1023/A:1021395726060

Ćirić-Marjanović G (2013) Recent advances in polyaniline research: polymerization mechanisms, structural aspects, properties and applications. Synthetic Met 177:1-47. doi: 10.1016/ j.synthmet.2013.06.004

Dmitrieva E, Dunsch L (2011) How linear is "linear" polyaniline? J Phys Chem B 115(20):6401-6411. doi: 10.1021/jp200599f

Dreyer DR, Park S, Bielawski CW, Ruoff RS (2010) The chemistry of graphene oxide. Chem Soc Rev 39:228-240. doi: 10.1039/B917103G

Feng XM, Li RM, Ma YW, Chen RF, Shi NE, Fan QL, Huang W (2011) One-step electrochemical synthesis of graphene/ polyaniline composite film and its applications. Adv Funct Mater 21(15):29892996. doi: 10.1002/adfm.201100038

Gupta RK, Alahmed ZA, Yakuphanoglu F (2013) Graphene oxide based low cost battery. Mater Lett 112:75-77. doi: 10.1016/ j.matlet.2013.09.011

Kim H, Abdala AA, Macosko CW (2010) Graphene/polymer nanocomposites. Macromolecules 43(16):6515-6530. doi: 10.1021/ma100572e

Maia DJ, De Paoli MA, Alves OL, Zarbin AJG, Neves S (2000) Síntese de polímeros condutores em matrizes hospedeiras. Quím Nova 23(2):204-215. doi: 10.1590/S0100-40422000000200011

Mi H, Zhang X, Yang S, Ye X, Luo J (2008) Polyaniline nanofibers as the electrode material for supercapacitors. Mater Chem Phys 112(1):127-131. doi: 10.1016/j.matchemphys.2008.05.022

Michell E, Candler J, De Souza F, Gupta RK, Gupta BK, Dong LF (2015) High performance supercapacitor based on multilayer of polyaniline and graphene oxide. Synthetic Met 199:214-218. doi: 10.1016/ j.synthmet.2014.11.028

Padilha RMA (2011) Estudo de transporte de cargas de polímeros de polianilina (Master's thesis). Rio de Janeiro: Pontifícia Universidade Católica.

Rakic A, Bajuk-Bogdanović D, Mojović M, Ćirić-Marjanović G, Milojević-Rakić M, Mentus S, Marjanović B, Trchová M, Stejskal $J$ (2011) Oxidation of aniline in dopant-free template-free dilute reaction media. Mater Chem Phys 127(3):501-510. doi: 10.1016/ j.matchemphys.2011.02.047

Sapurina IY, Stejskal J (2010) The effect of $\mathrm{pH}$ on the oxidative polymerization of aniline and the morphology and properties of products. Russian Chemical Review 79(12):1123-1143. doi: 10.1070/RC2010v079n12ABEH004140

Singh V, Joung D, Zhai L, Das S, Khondaker SI, Seal S (2011) Graphene based materials: past, present and future. Progr Mater Sci 56(8):1178-1271. doi: 10.1016/j.pmatsci.2011.03.003

Smith AL (1979) Applied infrared spectroscopy: fundamentals, techniques, and analytical problem-solving. New York: WileyInterscience.

Tamburria E, Orlanducci S, Guglielmotti V, Reina G, Rossi M, Terranova ML (2011) Engineering detonation nanodiamond polyaniline composites by electrochemical routes: structural features and functional characterizations. Polymer 52(22):5001-5008. doi: 10.1016/j.polymer.2011.09.003 
Tang J (1988) Infrared spectra of soluble polyaniline. Synthetic Met 24:231-238. doi: 10.1016/0379-6779(88)90261-5

Wang H, Hao Q, Yang X, Lu L, Wang X (2009) Graphene oxide doped polyaniline for supercapacitors. Electrochem Comm 11(6):11581161. doi: 10.1016/j.elecom.2009.03.036

Wang $H$, Hao Q, Yang X, Lu L, Wang X (2010) Effect of graphene oxide on the properties of its composite with polyaniline. ACS Appl Mater Interfaces 2(3):821-828. doi: 10.1021/am900815k

Wei P, Fan M, Chen H, Yang X, Wu H, Chen J, Li T, Zeng L, Zou Y (2015) High-capacity graphene/sulfur/polyaniline ternary composite cathodes with stable cycling performance. Electrochimica Acta
174:963-969. doi: 10.1016/j.electacta.2015.06.052

Yang JE, Jang I, Kim M, Baeck SH, Hwang S, Shim SE (2013) Electrochemically polymerized vine-like nanostructured polyaniline on activated carbon nanofibers for supercapacitor. Electrochim Acta 111:136-143. doi: 10.1016/j.electacta.2013.07.183

Zeng XR, Ko TM (1998) Structures and properties of chemically reduced polyanilines. Polymer 39(5):1187-1195. doi: 10.1016/ s0032-3861(97)00381-9

Zhang K, Zhang LL, Zhao XS, Wu J (2010) Graphene/polyaniline nanofiber composites as supercapacitor electrodes. Chem Mater 22(4):1392-1401. doi: 10.1021/cm902876u 